\title{
Eu, nativo, nós, lalanawinai. Reflexões baniwa sobre a alteridade branca ${ }^{1}$
}

\author{
JoÁo Jackson Bezerra Vianna
}

\begin{abstract}
resumo $\mathrm{O}$ trabalho de campo tem implicaçóes que extrapolam, em várias ordens, os objetivos da pesquisa. $\mathrm{Na}$ vivência antropológica, o pesquisador observa e experiencia questóes intelectuais muito variadas, e não somente de sua parte. Neste artigo, descrevo e analiso, particularmente, as questóes que os Baniwa - povo que vive às margens do rio Içana e seus afluentes no Noroeste Amazônico - fizeram com intuito de entender a mim, durante meu trabalho de campo. A tentativa é a de deixar vir à tona uma antropologia baniwa, avaliando se podemos entendê-la como reversa, no sentido atribuído por Roy Wagner. O resultado destas reflexôes aponta para a compreensão baniwa da alteridade dos brancos, assinalando quem somos nós, os Ialanawinai
\end{abstract}

palavras-chave Antropologia reversa. Baniwa. Cosmogonia. Corpo. Sexualidade

\section{Introduçáo}

Meu trabalho de campo ocorreu entre comunidades $^{2}$ do médio rio Içana - Alto Rio Negro, Noroeste Amazônico -, para pesquisa de mestrado que tinha como objetivo geral compreender o entendimento baniwa de adoecimento ${ }^{3}$. Mas não só concepçóes de doenças foram produzidas. Da minha vivência com os Baniwa, outras questôes muito variadas surgiram, e não só da minha parte. Neste artigo, descrevo e analiso, particularmente, aquelas que eles fizeram com intuito de entender a mim. A tentativa é a de deixar vir à tona reflexôes nativas e, talvez, nesse sentido, uma antropologia baniwa, que traduz em seus termos o pesquisador estrangeiro, no caso eu.

Estas experiências podem ser iluminadas pelas ideias de Roy Wagner (2010), autor que se dedicou a pensar uma noção de reversibilidade na tentativa de compreender a reflexividade daqueles que são estudados pelos antropólogos. Pretendo, a partir disso, testar aproximaçóes entre o que chamo neste trabalho de "antropologia baniwa” e o que Wagner descreve como "antropologia reversa".

Deste objetivo geral é preciso esclarecer duas questóes importantes: a primeira é que uma antropologia baniwa (ou reversa), se existe, não é exatamente a mesma que fazemos nos meios acadêmicos, sob seus critérios, de modo que a descrição deste trabalho é de uma antropologia que não estritamente a nossa; o segundo ponto é que a proposta, tal como foi lançada até agora, pode dar impressão de que sou o primeiro "branco" a andar em território baniwa, o que não é verdade. Este povo, já no século XVIII, possuía contato contínuo com os não índios (Wright, 2005). No entanto, quero enfatizar que tais encontros, por mais habituais que sejam, estão permeados por diferenças e distanciamentos - a despeito da secularidade das relaçóes travadas entre estas sociedades e de suas proximidades. E é exatamente deste hiato - no sentido de um encontro de termos dissonantes, implicando em incompreensóes mútuas, que partem de mim em relação aos Baniwa 
e deles a meu respeito - que pretendo tirar as reflexões para este trabalho, interessado mais nas incompreensóes reversas que fluem deles em direção a nós, os Ialanawinaí.

A ideia de um hiato pretende assinalar um encontro em que os distintos entendimentos, não obstante não estarem dados de antemão, têm seus termos relacionados: afinal há, apesar das equivocações, uma continuidade de sentido que possibilita a inteligibilidade (dos termos) do Outro, para ambas as partes. Pretendo, assim, revelar também as compreensóes sobre quem somos nós, pesquisadores brancos, do ponto de vista baniwa, e não somente, como disse há pouco, o que eles não compreendem de nós.

\section{A invenção da cultura, reversibilidade e antropologia}

$\mathrm{Na}$ esteira de Marylin Strathern, Viveiros de Castro (2004) descreve o fazer antropológico partindo da noçáo de cultura, definida como um gigante e multidimensional processo de comparação, um conjunto de analogias criativamente estabelecido entre diferentes domínios. Para esta mesma ideia, poderíamos utilizar os termos de Wagner, que se dedicou a compreender a noção de cultura, e dizer que, ao invés de 'comparando', estamos sempre 'inventando' estas relaçōes, uma vez que os termos da relação não existem por si. Nesse sentido, o autor diz:

Invenção, portanto, é cultura, e pode ser útil pensar todos os seres humanos, onde quer que estejam, como 'pesquisadores de campo' que controlam o choque cultural da experiência cotidiana mediante todo tipo de 'regras', tradiçóes e fatos imaginados e construídos. O antropólo- go torna suas experiências compreensíveis (para si mesmo e para outros em sua sociedade) ao percebê-las e entendê-las em termos de seu próprio modo de vida, de sua Cultura. Ele as inventa como 'cultura' (Wagner, 2010, p. 75).

O que autores como Viveiros de Castro, Wagner e Strathern sugerem é que todas as pessoas, ao viverem e experienciarem o mundo, criam comparaçôes, compatibilidades e analogias. Inventam, assim, cultura, tornando inteligível aquilo que se vive em uma dimensão encarnada - complexa demais -, e que só pode ser comunicado quando "reduzido" aos termos objetivos da sua própria cultura. É isto que o antropólogo acadêmico faz a partir de critérios próprios à disciplina antropológica, objetificando em textos a cultura observada/ vivenciada; e é isso também que os "nativos" fazem, mas a partir de seus próprios critérios, objetificando o Outro e o seu mundo em um domínio que não necessariamente é o da escrita e o da academia e nem mesmo a partir das mesmas categorias conceituais mediadoras. De qualquer forma, desenha-se uma continuidade entre metodologias diferenciadas, mas que seriam, antes, variaçóes ou facetas de um mesmo procedimento: o estabelecimento de analogias, comparações e compatibilidades.

Estas questóes indicam que, se comparamos ou inventamos os "nossos nativos", fazendo isso a partir de nosso próprio mundo, o mesmo ocorre no sentido inverso - ainda que o percurso não seja o mesmo nos dois sentidos (Viveiros de Castro, 2004) -, pois somos nós também comparados e inventados por aqueles que estudamos, a partir, escusado dizer, de seus próprios mundos. Essa reflexão acena para uma equivalência entre as diferentes formas de conhecer, comparar e lidar com alteridade de antropólogos e nativos, e nativos antropólogos. 
É importante atentar, porém, para o fato de que apesar destas comparaçóes, em diferentes fluxos, serem realizadas continuamente, elas não asseguram, por esta razão, uma traduzibilidade direta, de modo que a sinalizada continuidade entre as diferentes formas de conhecer e lidar com alteridade não atesta uma transparência epistemológica. Para Viveiros de Castro (id., ibidem), tomar essas comparaçóes - que fluem de nós para eles e deles para nós - como se fossem transparentes, dadas imediatamente, configura um equívoco, não porque haveria aí uma "falha no entendimento", mas uma falha em entender que os entendimentos não são necessariamente os mesmos. E que, de resto, o pretenso entendimento antropológico só pode ser formulado nos termos do controle de equívocos, e não nos termos de sua dissipação ou completa dissolução: um modo de lidar e não de resolver os paradoxos, haja vista serem estes não só incontornáveis, mas sobretudo produtivos.

Sobre esta equivalência metodológica em Wagner, Gordon alerta:

É claro que Wagner não imagina que todos são antropólogos da mesma forma - como, de resto, tampouco nativos -, mas apenas que é possível tratar os procedimentos de conhecimento nativos em continuidade às formas antropológicas de conhecer. Em suma, a afirmação de Wagner produz imediatamente uma reconceitualização do que seja a antropologia. A antropologia deixa de ser uma característica cultural (um atributo culturalmente específico: o modo pelo qual nós, 'ocidentais', conhecemos o Outro) e passa a ser o nome da relaçáo entre modos diversos de lidar com a alteridade (s/d).

O argumento de Wagner (2010) joga constantemente com as diferenças, erigindo-as e, por vezes, exagerando-as, para logo em seguida desconstruí-las, revelando sua artificialidade. É nesse sentido que Gordon utiliza dois recursos, quase simultâneos, para analisar a ideia de uma antropologia reversa na obra de Wagner: primeiro, aponta a diferenciação das antropologias, acadêmicas e nativas, pois, como comentou, Wagner "não imagina que todos são antropólogos da mesma forma”; em seguida, aproxima-as novamente, para indicar uma continuidade nos modos de pensar e lidar com a alteridade, que é a própria definição de antropologia em seu sentido amplo.

Wagner assinala, por um lado, a respeito das diferenças entre as antropologias, que cada tradição ou sociedade apresenta um conceito mediador diferente, capaz de objetificar o Outro. Para a nossa antropologia acadêmica, "ocidental", ele aponta a cultura como sendo esta categoria, enquanto que, para outras tradiçôes, isso muda. Na Melanésia, por exemplo, o autor sugere a noção de "carga", kago como dizem os melanésios, - que objetifica o lucro, o trabalho assalariado e a produção pela produção - como um modo nativo de literalizar aspectos caros aos ocidentais, sugerindo ser esta a contrapartida interpretativa de cultura, seu antissímbolo. Em outras palavras, quando nós observamos e vivenciamos a vida dos nativos, a designamos como cultura, e quando eles, melanésios, observam e vivenciam a nossa vida, a categorizam a partir da noçáo de carga.

No entanto, esta diferença não é tão fundamental a ponto de configurar procedimentos completamente díspares. Wagner identifica uma continuidade entre estas diferentes tradiçóes, reconceitualizando - como apontou Gordon - o termo antropologia, que passa a nomear não mais um modo de fazer Ciência, exclusivo aos ocidentais, mas uma relação entre as diversas maneiras de pensar e lidar com a alteridade. Estas relaçóes são o resultado de 
'comparações' e/ou 'invençôes' que findam na produção de uma determinada 'cultura', inventada para determinados 'outros'. Se, desta maneira, todas as pessoas inventam ou criam algo como uma cultura para sua alteridade, talvez seja possível apontar também que todos fazem antropologia.

Geertz (1997) alerta-nos que "todos são nativos" e, por isso, objetos de investigação e reflexão, em que pese a importância de entender, por exemplo, o pensamento moderno. Por outro lado, Wagner (2010) diz: "todos são antropólogos" - agentes que comparam e inventam o seu Outro e seu mundo. Esta última proposta promove uma mudança interessante de perspectiva, que faz ver a nós como nativos, objetos de reflexão, ao mesmo tempo em que faz ver os Outros que estudamos como antropólogos, agentes intelectuais, produtores de reflexôes. Deixamos, com isso, de ser nativos somente de nós mesmos, como entenderia a antropologia que pretende estudar a si por si, e passamos a ser nativos dos Outros que estudamos. É um redirecionamento de foco revelador de fluxos simultâneos ocorrendo em sentidos inversos, dentro de um mesmo processo e que revelam possibilidades analíticas que não exclusivamente as nossas teorias. Sublinhemos, mais uma vez, a possibilidade desta reflexão nativa ter um estatuto diferente daquilo que nós, antropólogos acadêmicos, concebemos como ponderação intelectual válida: passível de se evidenciar em práticas e simbolizaçóes, Wagner (2010) sugere pensar estas reflexóes natuvas como um gênero mais pragmático de antropologia. Nesse sentido, Sztutman comenta: “'nós' criamos uma disciplina especializada para fazer esse trabalho - a antropologia como ensinada na universidade -, enquanto 'eles' não separam essa reflexão de suas próprias vidas” (2009, p.112).

Desta reflexividade reversa apontada por Wagner como uma forma de um gênero mais pragmático de antropologia, pois colada às vidas dos que a praticam, Sztutman (2009) propõe como "excelentes exemplos" os filmes de Jean Rouch, em especial Os mestres loucos de 1954. Neste trabalho o antropólogo-cineasta registra um ritual africano de possessão da "seita" dos Hauka em que os participantes todos migrantes de Accra, cidade da Costa do Ouro (atual Gana) - incorporam deuses que possuem a forma de colonizadores. A um primeiro olhar o ritual seria uma imitação, mas deixando de lado a ideia de um simulacro, essas pessoas experimentam ser, em transe, generais, secretários de Estado, madames e governadores. Rouch definiu o ritual como "um reflexo da nossa sociedade", mas seria, talvez, mais apropriado interpretar o ritual como a reflexáo hauka sobre a nossa sociedade. Essa reformulação produz uma forma de ver o ritual que coloca estas pessoas não somente reagindo a uma situação de exploração, mas também refletindo sobre a situação de contato.

Deve ficar evidente, para fins teóricos e metodológicos, que considerarei cultura como o resultado de 'comparação' e/ou 'invenção', ou seja, como conceito que nós utilizamos para mediar os distintos domínios, nosso em relação aos dos outros, mas ao mesmo tempo, é importante admitir que todas as pessoas possuam também essa capacidade comparativa e que, portanto, inventam categorias mediadoras capazes de modular determinadas relaçôes. Assim, é possível dizer que todos comparam e inventam e fazem, por isso, em algum sentido, antropologia. Desse modo, o objetivo deste artigo é descobrir que Outros somos para os Baniwa, a partir de sua antropologia, e tentar, em alguma medida, delinear o fluxo etnográfico reverso. Procuro aqui perseguir categorias, percepçôes e modos baniwa de lidar com a alteridade branca, a partir do encontro com um pesquisador que precisa imaginar que os 
Baniwa têm cultura, quero dizer, modos criativos de invenção e comparaçâo.

\section{Nós, os Ialanawinai}

Ao entrar em campo descobri rapidamente o que significava a palavra ialanawi: isso porque as pessoas apontavam para mim e diziam-na o tempo todo. Seja ao me apresentarem uns para os outros, seja nas conversas que eles, os Baniwa, travavam tranquilamente entre si na certeza, e com razão, de que eu não entenderia nada. Não me foi difícil atentar para a premência de tal atribuição. Passei, porém, em meio à incompreensão que não era só linguística, a compreender que ialanawi era uma palavra para se referirem a mim, ou melhor, aos brancos como um todo. Contudo, não tinha certeza sobre o que se podia entender de fato por "brancos". Entre outras coisas, esta categoria não se restringia a identificar simplesmente as pessoas com um tom de pele específico, compreendendo características mais complexas que eu não dominava.

Tudo o que eu sabia, a esta altura, é que ialanawi eram as pessoas que de algum modo eram como eu. Mas o que emerge dessa dedução é: como são as pessoas que são como eu? Eu tinha algumas pistas para esta questão, obtidas tanto na convivência com os Baniwa quanto na literatura etnológica e, portanto, mesmo sem compreender completamente as categorias sobre nós, os brancos, era possível supor algo. Ialanawi é um designador de pessoas "não $\mathrm{Ba}$ niwa" e "não indígenas", com um habitus específico que os denunciam ser de um mundo, algo distante, o que em termos rio negrinos significa as fronteiras além São Gabriel da Cachoeira ${ }^{6}$. Exemplos claros desta categoria de pessoas são os pesquisadores acadêmicos (antropólogos, biólogos, linguistas), os pesquisadores ligados a ONGs e outros (fotógrafos, jornalistas, financiadores de projetos) que com menor frequência circulam também nas comunidades ao longo dos rios. Todos estes são frequentemente pensados como vindos de São Paulo, principalmente quando brancos (e agora me refiro ao tom da pele). A esta categoria dos brancos é possível incluir os profissionais de saúde do $\mathrm{DSEI}^{7}$, tais como auxiliares de enfermagem, odontólogos, enfermeiros e médicos.

Era possível entender que, do ponto de vista baniwa, havia em mim aspectos característicos de uma categoria específica de pessoas. Descobri, assim, que eu era um ialanawi pertencente ao coletivo dos Ialanawinai ${ }^{8}$. É preciso dizer que esta classificação corresponde a mais uma categoria inserida no plano da taxonomia social baniwa: assim como existem os Wakuenai ("os que falam nossa língua”, uma autodenominação para nomear as diferentes fratrias e sibs, os Makunai ("os que não falam nossa língua" para se referir a todos os outros povos indígenas), haviam também os Ialanawinai (Wright, 2000; Hill, 2000). Naturalmente, esta classificação baniwa contrastava com a percepção que eu tinha de mim mesmo, pois a ideia de que existiam pessoas que são como eu parecia-me um tanto abstrata e mesmo inexistente. Sinto-me brasileiro, acadêmico, ocidental e outras identidades que, como estas, estou habituado a assumir, mas ialanawi/branco, não. Vi-me, então, submetido a uma classificação estranha e externa.

Estas reflexóes, vale ressaltar, foram produzidas a posteriori, pois durante a vivência entre estas pessoas fui assumindo sem crítica, em uma ordem pragmática, um 'nós Ialanawinai. Aceitava quando diziam que eu era um e acabei adotando uma identidade que até então era externa, mas importante naquela vivência entre os Baniwa. Utilizava, sem consciência, o termo como um modo de facilitar certos diálogos 
e explicaçóes a respeito de mim e do lugar de onde eu vinha, que não era, para eles, somente meu, mas de todos os ialanawi. Algo comparável aconteceu e acontece no sentido inverso do fluxo que descrevi há pouco, quando nós, os brancos, dizemos que determinadas pessoas são indígenas. Recentemente estive no Baixo Rio Negro, em uma comunidade que reúne pessoas de diferentes grupos étnicos (Tukano, Dessana, Baniwa, Baré e Piratapuia) e ouvi, nessa ocasião, os "índios" falando dos indígenas como se fosse algo ao qual não estivessem incluídos, não que não se reconhecessem assim, mas é que de fato esse não é o modo próprio, entre eles, de se classificarem socialmente.

Alguns autores (Erikson, 1993; Gallois, 2007; Grupioni, 2009; Passes, 2006) têm demonstrado que nas ontologias sociais ameríndias os etnônimos ocultam uma série de diferenciaçóes que, na maioria das vezes, são os modos próprios destes povos se identificarem socialmente. Esta análise acaba revelando que a categoria ainda mais ampla - "índios" - está muito distante da concepção que estas pessoas têm de si, o que nos deixa em condiçóes de dizer que, do ponto de vista deles, não fazem parte de uma categoria abrangente deste tipo, a não ser estrategicamente em contexto multiétnico.

Ainda sobre essa experiência no Baixo Rio Negro, observei, por exemplo, na tentativa dos "índios" explicarem seus habitos alimentares à equipe de saúde, relatos do tipo "os indígenas comem isso assim”. Nota-se que não era um, "nós comemos isso assim". Sendo eles, ao longo do curso do rio, de diferentes etnias, não poderiam dizer 'nós': o pronome só poderia ser outro: 'eles', os indígenas. Acionava-se, assim, uma categoria que nossa sociedade inventou, mas apropriada por eles para operar estas relaçôes. Para este contexto, era adequado que eles utilizassem as categorias operadoras das relações multiétnicas, dado que suas próprias categorias tornariam, muito provavelmente, o diálogo intercultural impraticável. Essas pessoas compreendem muito bem nossa antropologia sobre eles e sabem lidar com as nossas categorias sem criar contradiçóes com as suas. De qualquer forma, este desencontro revela a fragilidade da ampla e estranha categoria - de "índios" - à ordem ontológica daquelas pessoas e coletivos.

O nosso esforço antropológico - e não me refiro necessariamente à antropologia acadêmica, mas ao modo como, por exemplo, o Estado (os serviços de saúde, educação e as demais ações indigenistas) atua - muitas vezes identifica estruturas ou um fundo cultural. Em contrapartida, do ponto de vista destes povos há, entre os diferentes grupos, diferenças enormes que devem ser marcadas: os Makunai para os Baniwa podem ser, por exemplo, tão diferentes deles quantos os Ialanawinai. Fato, não obstante, que contrasta com a perspectiva dos brancos, pois mesmo considerando as diferenças, procuramos semelhanças e as inventamos como uma cultura indígena.

Não quero reafirmar uma dicotomia arbitrária, entre o ocidental e o indígena, como se as categorias advindas do contato não pudessem ser apropriadas e, por isso, constitutivas da ordem conceitual destes povos. Mas também não se quer cair na indiferenciação dos termos, ou seja, no argumento de que tudo que é de fora se transforma facilmente em uma ordem indígena, sem maiores problematizações, a despeito das diferenças, como se elas não existissem ou não fossem produtivas: em que pesem as sutilezas propriamente indígenas em fazê-lo. Não parece adequado incluir à noção da apropriação diferentes processos e eventos, apagando as distâncias implicadas neste ínterim. É preciso, então, mostrar quais elementos são transformados por eles em cada caso, e quais não são - já que sempre há uma seleção -, e 
como isso se dá para diferentes elementos e diferentes situaçóes.

Não é suficiente dizer que a categoria "indígena" foi apropriada e, por isso mesmo, indigenizada, para usar os termos do Sahlins (1997), pois isso não esclarece tudo a respeito da utilização desta categoria pelos índios. É possível fazer um exercício nesta direção, ao situar um processo semelhante, mas em reverso. Retomo, para tanto, o que ocorreu comigo em trabalho de campo. Guardando as devidas diferenças, posso dizer que eu me apropriei de um termo indígena em um contexto específico para operar as relaçóes que se mostraram imperativas, o que não suprimiu, por completo, o meu estranhamento ao referirem a mim como sendo um ialanawi. A categoria já não era, de fato, completamente externa, mas também não era nativa (minha).

Se por um lado os índios se apropriaram do mundo moderno e de seus conceitos, transformando-os, à sua própria estrutura; por outro lado, eu me apropriei dos conceitos deles para meus próprios fins, transformando-os também - de modo que se eles indigenizam a modernidade, eu, naquele momento, ocidentalizei (ou modernizei) os aspectos indígenas. Essa 'modernização (ocidentalização) do que é indígena’ é o mesmo que propôs Sahlins com a 'indigenização da modernidade', mas ao avesso. Eu fui o nativo ao ver conceitos se impondo a mim e dos quais me apropriei com fins que não os "originais", mas meus próprios. Considerando que a apropriação transforma - o "apropriado" não é simplesmente isso, mas outra coisa que não aquilo que foi transformado -, eu admitia ser um ialanawi, mas não exatamente por concordar com os Baniwa ou por compreender precisamente o que eles queriam dizer sob este signo.

Chegamos por essa via a uma equivalência conceitual, que não significa uma correspondência direta entre os diferentes domínios, mas que revela agências antropológicas outras, chamando a nossa atenção para teorias e perspectivas indígenas. Os antropólogos são autorizados pela comunidade científica - e, deste modo, por nossa sociedade - a responder quem são os índios, categoria que a própria sociedade ocidental criou; em contrapartida, os Baniwa podem dizer quem são os ialanawi, conceito que também foi inventado. E, assim, como não sabemos tudo sobre eles, o que justifica infindáveis pesquisas e investigaçóes, eles não acham que sabem tudo dos brancos e persistem também na tentativa de entender quem somos nós.

Um exemplo notável desta tentativa em entender os brancos é dada pelo xamã yanomami Davi Kopenawa e o antropólogo Bruce Albert (Kopenawa \& Albert, 2010). No trabalho produzidos por estes autores há um esforço reflexivo importante que, além de lançar luz sobre os sentidos do contato interétnico de um ponto de vista nativo, descreve a objetificação yanomami dos brancos. Para Kopenawa, as pessoas que invadem as terras yanomami, os garimpeiros, são como espíritos maléficos, filhos de comedores de terra que chafurdam na lama, dia e noite, em busca do ouro e outros metais preciosos que, por seu potencial destrutivo e patogênico, foram colocados embaixo da terra por Omamë, o demiurgo.

A violência predatória associada aos brancos é atribuída por Kopenawa à ignorância destes, cujos pensamentos estão "plantados nas mercadorias" e, por isso, mergulhados em uma "escuridão confusa" que os impossibilita de ver/ conhecer as coisas. De acordo com ele: "Vocês, brancos, vocês mentem. Não vêem-conhecem as coisas. Vocês acham que as conhecem, mas só vêem os desenhos de sua escrita" (Albert, 1995, p. 11). A escrita é, segundo Albert, para os Yanomami, um simulacro de "visão" e, portanto, de "conhecer", que remete ao domínio dos manufaturados e das máquinas. Nota-se, com isso, 
I6o | Joấo Jackson Bezerra Vianna

uma antropologia yanomami que entende os brancos a partir da noção mercantil, cujo desdobramento é a ideia da "predação mercantil", tal como apontou Albert. Neste caso, a predação seria decorrente do valor conferido pelos brancos às máquinas, manufaturas e coisas possuidoras de valor mercatório que desconsidera a ecologia cosmológica expressa por Davi Kopenawa.

À luz destas questóes é possível apontar que por ialanawi (ou por "brancos") os Baniwa não somente identificam as pessoas que não são indígenas, e assim como os Yanomami compreendem os que invadem a sua terra, explicando as ações predatórias destes a partir de uma noção mercantil, os Baniwa estão interessados na compreensáo do substrato epistemológico que fundamenta os modos de agir, pensar e fazer dos brancos. Com o intuito de trazer à tona estes aspectos, relatarei, a partir de agora, experiências que podem nos dar pistas sobre quem são os Ialanawinai. Para tanto, organizarei, sob dois tópicos diferentes, experiências que potencialmente podem produzir estes indícios explicativos: cosmogonia e corpos.

\section{"Branco não come macaco". Cosmo- gonia Ialanawinai}

Os Baniwa me deram uma classificação social e também um mundo social, atribuído a todos os ialanawi, como deve ter ficado claro acima. Mas não foi somente isso, pois algo como uma natureza e/ou cosmologia ${ }^{9}$, que sustenta e preenche este mundo branco, foi também conferido a mim. Eles percebem que nós (estou chamando de "nós" o que eles denominam de ialanawi/branco) acionamos esta "natureza” - representada, entre outros aspectos, pela ciência, suas técnicas, teorias, ou, como disse Kopenawa, "mercadorias" - para explicar uma série de fenômenos que, sabem, é diferente do que ocorre para eles mesmos. Descobri, ao me deparar com essas questôes, um mundo que os Baniwa haviam inventado para mim, com o intuito de explicar minhas açóes, no sentido wagneriano, do mesmo modo em que eu me esforçava para inventar um mundo/cultura para eles, com o mesmo intuito que eles.

Para pensar se Natureza ou se Cosmologia (Cultura) nomeia melhor aquilo que os indígenas da Amazônia veem em nós, é interessante retomar a proposta elaborada por Viveiros de Castro (1996), quando assinala que nós Ocidentais concebemos um multiculturalismo e, inversamente, os ameríndios um multinaturalismo. Considerando este argumento, seria, talvez, mais apropriado supor que eles veem em nós uma natureza diferenciada e não uma cultura diferente. Todavia, ocorre também que, para os ameríndios, cosmologia e natureza possuem um estatuto diferenciado e não obedecem as dicotomias do mesmo modo que para nós. Nesse sentido, Viveiros de Castro propóe que recombinemos essas noçóes para em seguida

[as] dessubstancializar, pois as categorias de $\mathrm{Na}$ tureza e Cultura, no pensamento ameríndio, não só não subsumem os mesmos conteúdos, como náo possuem o mesmo estatuto de seus análogos ocidentais - elas não designam províncias ontológicas, mas apontam para contextos relacionais, perspectivas móveis, em suma, pontos de vista (Viveiros de Castro, 1996, p. 116)

Sendo assim, ao se dizer que os Baniwa veem nos ialanawi uma natureza ou cosmologia particular, se estará incorrendo, como já foi dito, a uma equivocação, mas espera-se que a uma equivocação controlada, pois na falta de termos mais apropriados, partirei dos termos 
conhecidos, distorcendo-os, na expectativa de que eles se transformem e comuniquem coisas outras (ver Viveiros de Castro, 2004).

Em uma das entrevistas realizadas durante minha pesquisa, na comunidade de Tunuí Cachoeira, no médio rio Içana, seguiu-se uma conversa em que Alonsio Gentio - jovem professor da escola Maadzero, localizada nesta mesma comunidade - comentou comigo algumas das suas reflexóes sobre o que ele chama "a história dos brancos":

Cada coisa tem história, cada povo tem sua história, o branco tem sua própria história. Olha o surgimento da humanidade. Na história dos brancos ela surge através dos macacos. [...] O mundo era quente, nesse mundo não vivia nenhum tipo de ser vivo, mas depois de 3,4 milhóes de anos começaram a aparecer os primeiros seres. São eles os dinossauros e as aves que têm dentes, e também as aves que têm unhas - esses seres começaram a aparecer neste ano. Durante este tempo o mundo foi se desenvolvendo e os animais começaram a desaparecer. Eu li a história dos brancos e comparando ela com a nossa realidade, têm algumas partes que combinam e outras que não. Algumas partes do branco são muito diferentes da história dos povos indígenas. Para os brancos o mundo surgiu no fogo, o mundo ficava tipo em vulcóes. Vulcóes, fogo, e tudo era assim, o mundo era fervido. A Terra era puro fogo mesmo. Mas quem que esfriou esse mundo? Atmosfera? Então, a atmosfera acumulava nuvens e depois de muitos anos começou a chover e é por isso que a Terra começou a resfriar. Depois disso a Terra ficou do jeito que é hoje, o mundo ficou resfriado e ficou assim: com morros, serras, e todas essas coisas. Desse surgimento, como eu falei, há 3,4 milhôes de anos atrás, surgiu o mundo, foi aí que surgiram os seres vivos nessa Terra. Mas isso tudo aí é hipótese dos cientistas. Cada qual acredita na sua história. Eu sempre brinco com os alunos: "Vocês sabem a nossa história, dos povos indígenas? Vocês sabem como surgiu o mundo? E na história da evangelização como é que surgiu o mundo? E na história dos brancos, como é que você interpreta esses três surgimentos do mundo? História do branco, história da evangelização e a nossa própria história. Como é que surgiu tudo isso?” A da evangelização é outra coisa, da nossa história é outra coisa, da história do branco é outra coisa... Mas é bom aprender... Por isso que a maioria dos brancos não comem macaco, porque para os brancos nós somos descendentes do macaco. [Eu intervenho neste momento dizendo "E os Baniwa, em compensação, comem macaco até...”. Seu Gentio, pai de Alonsio, que acompanhava a entrevista, mas não havia se manifestado até então, disse, rindo: "Ih... Come muito". E Alonsio: "Ah! Come à vontade". E eu disse, "Eu comi macaco uma vez, mas confesso que não gostei muito" - e então Alonsio retoma a palavra] . Mas é o seguinte, os macacos que estão lá são diferentes dos macacos que existem para cá, eles aqui não são iguais aos chipanzés e todos esses grandes macacos. [Eu pergunto: "Vocês dão aula sobre isso na escola?] É porque tem uma ciência que fala sobre isso, vem no livro. Eu entendo esse livro e, então, passo esse conhecimento para os alunos e em cima disso a gente compara com a nossa história. É assim que a gente vê as diferenças das histórias. Compara, então, para que? Para vocês é 3,4 milhões de anos, mas será que para cá, a gente já existia nesse ano? Então, esse ano a gente não sabe que ano que é isso, mas, na minha opinião, isso ai é só imaginação dos maiores cientistas que estudam sobre o mundo, isso ai não é verdade.

Nota-se nesta antropologia baniwa um conjunto determinado de característica dos 
I62 | Joấo JaCkson BezerRa Vianna

brancos, muito particular, capaz de explicar as atitudes dos ialanawi. O intelectual/ antropólogo baniwa ${ }^{10}$ em questão, a respeito das "histórias dos brancos," identificou o motivo pelo qual, por exemplo, eles (nós) não comem macaco: de acordo com sua observação, os Ialanawinai acreditam ter descendido dos macacos que, por isso, são seus ancestrais. Logo, para um branco, comer macaco seria uma espécie de transgressão cosmológica. Em contrapartida, algo análogo a essa concepção está completamente fora das possibilidades existenciais e míticas baniwa: afinal, macacos estão longe de explicar a origem dos humanos e representam, ao contrário, uma espécie de iguaria culinária.

A dietética baniwa possui implicaçóes que colocam interdiçôes e cuidados específicos para se comer carnes de qualquer origem ou mesmo produtos de origem vegetal, como a mandioca. Disse-me o senhor Alberto, benzedor ${ }^{11}$ baniwa da comunidade de Jandú Cachoeira, que todos os alimentos devem ser bem cozidos e benzidos antes de ingeridos. Segundo ele, mesmo os baniwa que são evangélicos fazem oração antes de qualquer refeição. Garnelo (2002, p. 135) alerta, nesse sentido, para o perigo do consumo de peixes mal cozidos entre os Baniwa, uma vez que "o 'pitiứ do peixe mal-cozido possibilita o crescimento de um peixe/serpente no intestino do doente", enfraquecendo-o. Segundo a autora, "o cheiro do alimento apodrecido é indicativo da capacidade agressora dos seres-espíritos da natureza”. A despeito destes aspectos quero chamar atenção para o fato de que há diferentes motivaçóes para as restrições alimentares dos brancos e dos índios. As implicaçôes em comer a carne de macaco são diferentes para ambos e é a esta restrição diferente encontrada nos brancos que Alonsio, em comparação a si mesmo e aos Baniwa, aponta.

Esta reflexão, quando comunicada por Alonsio, me atingiu fortemente, pois nunca havia cogitado esta possibilidade, sempre achei que não gostava da carne de macaco por uma simples questão de paladar e não por uma espécie de tabu alimentar com origem em uma interdição cosmológica. Ele surpreendeu-me com a minha própria teoria - que era na verdade uma teoria dele sobre mim e sobre o "meu grupo" - e me fez sentir, de certa forma, sem meias palavras, ridículo. Não era gratuita a sensação suscitada, afinal ele revelou, com sua antropologia, o caráter essencialmente simbólico das minhas predileçóes gastronômicas.

A situação inusitada, pelo menos para mim, mostrou-me de maneira nítida que também tenho uma cosmologia, que fundamenta minhas ações cotidianas e pensamentos, permeados de significados particulares. Talvez se trate especificamente do que Wagner já chamara a atenção, em sua obra $A$ invenção da cultura:

É apenas mediante uma "invenção" dessa ordem que o sentido abstrato da cultura (e de muitos outros conceitos) pode ser apreendido, e é apenas por meio do contraste experienciado que sua própria cultura se torna "visível". No ato de inventar outra cultura, o antropólogo inventa a sua própria e acaba por reinventar a própria noçâo de cultura (2010, p. 31).

A experiência com os Baniwa, e mais especificamente com Alonsio, tornou visível, com seus contornos, a minha própria cultura, revelando e ao mesmo tempo transformando o meu entendimento sobre mim mesmo e meu mundo. Essa tal cultura, quase sempre distante e atribuída aos Outros, passou a ser mais palpável e próxima. Essa experiência teve implicaçôes profundas, pois tornar a própria cultura visível nos leva a compreender que ela é também, como nós vemos nos Outros, do reino da ação humana e não do reino do dado. A isso Wagner 
chamou de relativização. Para o autor, este é o processo em que a pessoa se torna consciente da arbitrariedade do seu papel desempenhado na ativaçấo dos símbolos, afetando os controles que restringem o campo de visão consciente do simbolizador, e deixando assim, em certo grau, de mascarar a natureza simbólica de suas açóes.

A comparação dos hábitos alimentares marca diferenças entre os Baniwa e os Ialanawinai que vão além das ações em si e alcança fundamentos mais profundos. Pois se os brancos vieram do macaco, os Baniwa vieram da cachoeira de Hipana ${ }^{12}$ - para eles, uma teoria não abala a outra. Ressalta-se, entretanto, que os Baniwa têm uma teoria própria sobre a origem dos brancos, como vindos de Hipana também (Wright, 1999) e que, após isso, estes foram para além de Eenothani, um lugar onde o mundo acaba e o sol nasce. O rio Negro, segundo o senhor Alberto, encontra neste lugar algo como um muro e é depois dele que se situaram os brancos logo após a saída de Hipana. Mas não se trata disso neste momento, pois para este caso Alonsio não está a explicar os brancos a partir das concepções baniwa, mas a capturar as teorias ialanawi sobre eles mesmos, em uma antropologia que pretende compreender as categorias nativas.

Não havia um comprometimento de Alonsio em desmentir a nossa história, questionando Charles Darwin. No lugar disso, ele estava somente afirmando a sua própria "história", ao não concordar com a teoria do evolucionismo para as pessoas do rio Içana, o que náo significa que ela não tenha, para ele, validade para os brancos. As diferenças, em contextos ameríndios, estão situadas, como sugere Viveiros de Castro (1996), na chave do multinaturalismo e não na do multiculturalismo. Sobre isso o autor diz:

Esse reembaralhamento etnograficamente motivado das cartas conceituais leva-me a sugerir a expressão "multinaturalismo" para designar um dos traços contrastivos do pensamento ameríndio em relação às cosmologias "multiculturalistas" modernas: enquanto estas se apoiam na implicação mútua entre unicidade da natureza e multiplicidade das culturas - a primeira garantida pela universalidade objetiva dos corpos e da substância, a segunda gerada pela particularidade subjetiva dos espíritos e dos significados -, a concepção ameríndia suporia, ao contrário, uma unidade do espírito e uma diversidade dos corpos. A "cultura" ou o sujeito seriam aqui a forma do universal, a "natureza" ou o objeto a forma do particular (1996, p. 116).

Quando comentei com Alonsio que havia comido macaco e não gostado, ele imediatamente alertou: "os macacos que estão lá [no mundo dos brancos] são diferentes dos macacos que existem para cá", isto é, são de outra "natureza” (se inscrevem em outro domínio relacional) e, por isso, para os brancos, podem de fato ter originado os humanos. Por sua vez, os macacos do Içana, os animais caçáveis e qualquer outro ente que se apresenta como não-humano, não podem ser localizados como a origem humana/Baniwa. Estes seres, por este ponto de vista, não são pensados pelo mesmo regime que os brancos instituem - a origem animal dos humanos e sua "ascensão" evolutiva, via cultura, que os separou dos demais animais.

Se, por um lado, disto depreende-se diferenças de concepçóes acerca da origem e condição "evolutiva" humana, por outro, parece resvalar num comentário baniwa aos termos brancos de entendimento das progressóes das quais os humanos brancos, "acreditam", são resultados. Em diversas situações, alertaram-me os Baniwa: os animais, em seus mundos, são pessoas como nós, eles casam, tem fratrias e fazem festas. Diferente do que concebem os 
brancos, os animais baniwa, em seus mundos, são gente como nós: assim, não são seres inferiores ou menos complexos, pois igualmente providos de volição, intenção consciente, faculdades intelectuais e, portanto, tanto quanto nós, são pessoas humanas. $\mathrm{O}$ mundo Baniwa não impõe, nesse sentido, uma escala evolutiva passível de ser lida por marcos "morais", inferior/superior, que separa, sob este critério, animais e humanos; é um mundo em que todos são pessoas, cujas capacidades iguais e intençôes potencialmente diferentes devem ser consideradas.

Com estas questôes, a comparação entre os diferentes mitos de origem vem à tona. Nesta esteira, é interessante sublinhar o comentário Viveiros de Castro:

Era possível perceber também que o tema mítico da separação entre humanos e não-humanos, isto é, entre "cultura" e "natureza", para usarmos o jargão consagrado, não significava, no caso indígena, a mesma coisa que em nossa mitologia evolucionista. A proposição presente nos mitos indígenas é: os animais eram humanos e deixaram de sê-lo, a humanidade é o fundo comum da humanidade e da animalidade. Em nossa mitologia é o contrário: os humanos éramos animais e "deixamos" de sê-lo, com a emergência da cultura etc. Para nós, a condição genérica é a animalidade: "todo mundo" é animal, só que alguns (seres, espécies) são mais animais que os outros: nós, os humanos, certamente somos os menos animais de todos e “esse é o ponto", como se diz em inglês. Nas mitologias indígenas, muito ao contrário, todo mundo é humano, apenas alguns desses humanos são menos humanos que os outros. Vários animais são muito distantes dos humanos, mas são todos ou quase todos, na origem, humanos ou humanóides, antropomorfos ou, sobretudo, "antropológicos" isto é, comunicam-se com(o) os humanos (2008, p. 33).

A nossa chave evolucionista não opera com as mesmas referências no contexto ameríndio (se é que opera), de modo que o pensamento que formula a ideia que os macacos deram origem aos humanos é passível de ser apontado como uma diferença antropológica a ser interpretada, como fez Alonsio ao explicar a recusa de muitos brancos à carne de macaco. Do ponto de vista do pensamento euro-americano, o que fundamenta a relação entre macacos e homens, em termos de origem, é a lógica que concretiza uma escala evolutiva geral - envolvente, em uma só rede, dos diferentes seres vivos -, cujos critérios configuram-se a partir de pontos iniciais, indicadores de complexidades reduzidas, que em gradiente alcançam pontos finais, de complexidades acentuadas: macacos e depois humanos, células unicelulares e depois organismos multicelulares.

Além disso, esta mesma escala que inventa a origem animal do homem contra-inventa a não-humanidade dos animais - afinal, estes não "evoluíram", ficando, por isso, abismalmente distante dos humanos: exluidos da emergência cultural, aprisionados no domínio do natural, do instintivo e do irracional. Este entendimento desumaniza os animais e, por sua vez, a própria natureza; ao contrário do que ocorre para os Baniwa, em que tudo (ou quase tudo) é humano e, por isso, perigoso (Viveiros de Castro, 2008). Quando formuladas de um ponto de vista indígena, estas concepçóes têm implicaçóes importantes e desdobram-se em outras reflexóes, pois se os brancos possuem uma natureza desumanizada - desprovida de intenção e "espírito", incapaz de reagir deliberadamente às açóes humanas -, este é o motivo pelo qual eles, "nós os brancos", entendem que 
podem utilizar as florestas e o ambiente indiscriminadamente e, por consequência, destruí -la em limites elásticos.

De posse destas "observaçóes antropológicas” os índios compreendem a relação dos brancos com a natureza, constatando que esta relação é diferente da relação que eles próprios estabelecem, e a partir disso podem elaborá -la, como fez Davi Kopenawa, nos termos de uma Crítica Xamânica da Economia Política da Natureza. Segundo o xamã yanomami, esta concepção que permite aos brancos destruir a natureza, é uma ilusão - e é neste ponto que reside sua crítica, pois uma vez que os brancos não veem/conhecem as coisas da floresta tal qual os Yanomami, eles caem na escuridão da ignorância, não sabendo o real impacto deste modo de agir ao predar desmedidamente tudo o que é vivo no ambiente. Em seu argumento, Kopenawa afirma que os brancos não têm consciência destas ações provocarem "doenças que se alastram e matam todo mundo, não somente os Yanomami, mas os brancos também” (Albert, 1995, p. 11).

Aproxima-se à esta crítica ecológica de Kopenawa a reflexão que Alonsio elaborou ao delinear uma equivalência entre mito e ciência - que soa também como uma crítica ao modo branco de pensar, mas agora dirigida às suas relaçôes com o conhecimento indígena. Pois se os brancos definem como mito (de modo geral associando ao que não é real) aquilo que os Baniwa contam sobre sua origem, Alonsio assinala que a ciência é o mito do branco, pois produz teorias que, na verdade, são hipóteses, com origem na imaginação dos cientistas. Ou seja, ele localiza a nossa ciência em um reino da ação humana e não no reino do dado. A ciência - como aponta a reflexão baniwa - não é uma instituição que descobre fatos, mas produz dados apenas pensados, por nós brancos, como "naturais" e verdadeiros.
O cruzamento das antropologias, ocidental e baniwa, impóe a simetria, na medida em que faz mito e ciência caírem em relativização, visto que construídos - apesar de concebidos, em geral, como dados. O mito é pensado pelos índios como sendo da ordem do dado das coisas; já para os brancos são os fenômenos naturais e, portanto, a natureza, objeto de investigação da ciência, que ocupa esse espaço ${ }^{13}$.

Ainda sobre o relato de Alonsio, é possível notar mais uma pista para a categoria ialana$w i$, dada por ele ao operar uma diferenciação entre três diferentes histórias: a dos brancos, a da evangelização e a dos índios. A primeira é associada, claramente, à Ciência, como se esta desse a base de sustentação para a cosmologia dos que ele designa serem Ialanawinai. A segunda história é a da evangelização, não conferida por ele aos brancos: admite-se, no lugar, uma vinculação com certos brancos (exemplo dos missionários), mas não aos brancos enquanto categoria conceitual ampla. E a terceira história, contraponto para as outras duas, é a história dos Baniwa.

\section{Sobre Corpos}

Minha pesquisa para dissertação estava preocupada com as noçóes de adoecimento, como já foi dito, partindo de uma doença em específico que ocorre na escola Pamáali há mais ou menos oito anos. Essas doenças são provocadas pelos yóopinai, seres espírito que, grosso modo, vivem em conflito com os humanos. De modo geral, esses seres não podem ver as pessoas, mas há determinadas situações que tornam os humanos visíveis para eles, o que aumenta a chance de seus ataques e, consequentemente, do adoecimento dos humanos. A menstruação feminina é uma dessas ocasiões que criam 
visibilidade, bem como um estado chamado pelos Baniwa de khéewi, uma espécie de menstruação masculina. Em termos gerais, estar khéewi para um homem baniwa é ter sonhado com uma mulher e ter tido, por isso, polução.

Não importando tanto o conteúdo da temática investigada por mim, descreverei a forma como acessei estas questóes. Eu conversava sobre as doenças da Pamáali com um grupo de alunos desta escola com a ajuda de Abilio Julio, um jovem professor que traduzia para mim o que os sete jovens não conseguiam expressar em português. Nessa ocasião, me vi nativo, tendo que responder questóes sobre a sexualidade Ialanawinai:

Abílio: Os meninos querem saber, como é para vocês? Essa pergunta é direto para Ialanawinai (risos). Isso acontece com vocês? Eles querem saber se ialanawi, pha khéewika ialanawi? Ou seja, se ialanawi passa por aquele sonho também... [Eu respondo de imediato: "passa também”. E após uma pausa Abilio retoma a questão da seguinte forma] Mas isso significa para vocês o quê? É isso que queremos saber, interagir um pouquinho...

João: Nós temos sonhos também, desse tipo, mas para nós é diferente, porque os significados são outros. Para nós esses sonhos acontecem quando se está há muito tempo sem namorar.

Abílio: Mas é com uma pessoa conhecida ou não conhecida?

João: Geralmente é com pessoa conhecida, por exemplo, a namorada, mas ocorre também de sonhar com outras garotas.

Abilio: Como baniwa, ouvi Daniel comentando que para o estado khéewi há remédios tradicionais capazes de curar isso. Porque dizem os velhos, quanto mais as pessoas sonham dessa maneira mais elas envelheceram, e mais rápido. O remédio faz com que a pessoa não envelheça com rapidez.
Daniel: Quanto mais as pessoas sonham desta maneira, mais elas vão envelhecendo. Porque é como se elas estivessem fazendo relaçáo sexual de verdade, todos os dias. Sexo no sonho é como na realidade. Se uma pessoa estiver fazendo muito sexo, para nós, como baniwa, pode fazer com que envelheça mais rápido, eliminando a característica normal da pessoa.

Os alunos demonstravam com estas questóes uma curiosidade que era uma tentativa de compreender as diferenças, entre eles e os brancos, testando similaridades. Queriam saber, por exemplo, se os brancos, assim como eles, ficam khéewi, se os corpos eram, nesse sentido, iguais e capazes de produzir reaçôes análogas. Minha insatisfatória resposta os forçou a insistirem na questão, recorrendo aos significados destes sonhos para os brancos, ou seja, como se explica uma ação ou pensamento (no caso os sonhos) em uma "cosmologia branca", pareciam querer saber: o que diriam os nossos velhos a respeito?

A resposta que dei, de súbito, sem tempo para maiores reflexões, dava conta de uma falta, quase biológica, que cria um descompasso hormonal. Por conseguinte, a psique reage sublimando ${ }^{14}$, em sonhos, o que não pode ser realizado em realidade. A minha análise posterior sobre minha própria resposta identifica uma marcante concepção psicobiológica e, portanto, científica. Além do mais, há de se destacar que sinalizo para uma dicotomia entre realidade e sonho. O sonho, radicalmente diferente do período de vigília, é o local do reprimido, das possibilidades não realizadas; o mesmo, porém, não vale para eles, em absoluto.

Para os Baniwa, o ato sexual em sonho e em vigília tem o mesmo estatuto, produzem, por exemplo, de igual maneira, um envelhecimento precoce. Uma relação sexual em sonho não é menos real - e eis o perigo destes sonhos -, 
pois o que se vê em sonho como mulher é na verdade yóopinai e, nesse caso, se está estabelecendo um intercurso sexual com seres espíritos, não-humanos.

Estas diferenciações foram se desenhando para mim, do mesmo modo que para eles; os alunos também estavam interessados em saber os meus pensamentos, efetuando de modo semelhante um exercício contrastivo. Não sei ao certo o que eles pensaram das minhas respostas, pois não tive acesso às suas análises diante do material etnográfico obtido por eles, somente que constataram uma diferença.

Ainda sobre os corpos diferentes, dos Baniwa e Ialanawi, certa vez, me disseram: "engraçado, se a gente dormir muito faz mal, para vocês não, dormir é bom e faz bem, rejuvenesce". Com isso notei algumas constataçóes baniwa sobre nós ${ }^{15}$ : a de que dormíamos mais do que eles, dado que, de modo geral, íamos dormir antes e acordávamos depois de todos, mas isso tinha uma razão, um significado determinado. Conversando com a pessoa que fez o comentário, ele contou que viu em uma reportagem da televisão um pesquisador (provavelmente médico) falando sobre os benefícios do sono. Ele concluiu que para os brancos é assim mesmo, ao vê-los dormindo tanto e, com isso, confirmando a teoria vista na televisão: para branco dormir faz bem.

Um tempo depois, o mesmo comentador me explicou que os velhos baniwa contam que "na história" (um dos modos para se referirem ao tempo mítico) que havia um velho que dormia muito, e quanto mais ele dormia mais envelhecia. De modo que, para os Baniwa, dormir em demasia envelhece, causando prejuízos na formação da pessoa. A história do velho que dorme muito, todavia, não explica as açôes dos brancos, e o contrário também não, por motivos que acima já foram apontados.

\section{Consideraçóes Finais}

Pensar em uma antropologia reversa não retira do antropólogo a responsabilidade analítica e nem escamoteia sua agência no trabalho etnográfico, mas também não subestima a reflexão daqueles que são estudados. Talvez, por isso, seja mais apropriado conceber, como apontou Sztutman (2009, p. 112), a antropologia reversa como sendo "uma antropologia da antropologia feita pelos nativos", ou seja, é o antropólogo acadêmico que faz a antropologia reversa, considerando que em um reverso hajam reflexóes que podem ser pensadas como sendo uma forma de antropologia. O antropólogo acadêmico, assim, continua em cena atuando e, sem renunciar à sua posição, se esforça para não obliterar o fluxo etnográfico que tem origem não em si mesmo, mas no nativo, este que, como o antropólogo, procura entender o 'outro' colocado na relaçáo. Este empreendimento revela reflexóes estabelecidas em diferentes sentidos, mas para esta abordagem não é o nativo somente que está em questão ou o antropólogo simplesmente, mas este último e sua realidade através do primeiro.

A partir destas questóes procurei descrever a convergência de diferentes iniciativas intelectuais, a dos Baniwa e as minhas. Como resultado, foi possível alcançar uma antropologia baniwa que compreende os brancos como sendo diferentes deles mesmos, com base na diferença dos corpos/naturezas (multinaturalismo ameríndio). Nesse sentido, os dados apontam para reflexóes que identificam que os brancos concebem os animais (o que inclui o próprio homem, dado que, neste caso, a condição genérica é a animalidade) e os demais seres vivos do cosmos a partir de uma escala evolutiva, fato que explica, em parte, porque eles (nós) pensam o macaco como a origem humana. Esta 
mesma escala que identifica a origem animal do homem assinala mais que isso: a não humanidade dos animais. A referida não humanidade dos animais desumaniza a natureza, ao contrário das teorias ameríndias, em que a natureza é viva, povoada e constituída de seres dotados de "alma/espírito" (seres que, nesse sentido, são gente, humanos). Por sua vez, os brancos possuem uma natureza desumanizada, como se fosse morta, e, por isso, podem explorá-la sem censura. Reside neste ponto as críticas baniwa e yanomami, ao modo predatório/destrutivo dos brancos se relacionarem com a natureza.

Este trabalho tentou, a partir das reflexões nele contidas, demonstrar a maneira como os Baniwa compreendem as concepçóes e as açóes dos Ialanawinai. O que poderia possibilitar a nós (ocidentais modernos) um modo específico e um outro ponto de vista para pensar nossa sociedade. O desafio que este trabalho pretendeu suscitar é, assim, cruzar o pensamento deles sobre nós com nosso pensamento sobre nós mesmos.

\section{I, native, we, lalanawinai: Baniwa reflec- tions on white alterity}

abstract Fieldwork has implications that go beyond, in many ways, research objectives. In the anthropological experience, the researcher observes and experiences very different intellectual issues, and not only his. In this article, I describe and analyze, particularly, those that Baniwa - people who live on the banks of Içana River and its tributaries in the Northwest Amazon - posed with the intention of understanding myself during fieldwork. The attempt is to reveal a Baniwa anthropology and evaluate the possibility of understanding it as reverse, in the sense coined by Roy Wagner. The result of these considerations points to the understandings of Baniwa about white alterity, highlighting who we are, the Ialanawinai.

keywords Reverse Anthropology. Baniwa. Cosmogony. Body. Sexuality.

\section{Notas}

1. Esta pesquisa foi apoiada pelo Projeto Saúde e Condições de Vida de Povos Indígenas na Amazônia, Programa de Apoio a Núcleos de Excelência - PRONEX/ FAPEAM/CNPq, Edital 003/2009. Agradeço Milena Estorniolo, Íris Araujo, Luiza Garnelo e Nicole Soares pelos comentários, críticas e sugestóes a este texto.

2. Os Baniwa denominam seus grupos, ou assentamentos familiares, como 'comunidades' e, segundo Xavier (2008), sentem-se desconfortáveis quando alguém as denomina 'aldeias'.

3. Ver Vianna, 2012. A pesquisa, em sua faceta etnográfica, ocorreu em diferentes etapas. A primeira, entre os meses de janeiro e fevereiro de 2011, passei aproximadamente vinte dias percorrendo, de baixo ao alto do rio, as comunidades do Içana. Em um segundo momento, entre os meses de maio e junho deste mesmo ano, convivi por trinta dias com alunos e professores baniwa da escola-comunidade Pamáali localizada no médio rio Içana. Por fim, passei trinta dias viajando por comunidades baniwa do rio Içana. Houve ainda períodos na cidade de São Gabriel da Cachoeira, a mais próxima das comunidades do Içana, difíceis de quantificar, em que pude conversar, entrevistar e conviver com os Baniwa que conheci nestas viagens. Estes momentos, assim como aqueles vividos nas comunidades, foram importantes para os dados produzidos na pesquisa.

4. Os Baniwa traduzem este termo para o português como "os brancos". Wright (2000) dedicou-se a estudar esta categoria demonstrando como ela se construiu durante o período do contato e como isso se acomodou na mitologia, porém, o que proponho neste trabalho é diferente ao procurar capturar os modos como este conceito opera a relação com a alteridade do homem branco, sem a preocupação de situar esse processo em uma linha histórica ou em um panorama mítico circunscrito.

5. Ver também Sztutman, 2004, 2005.

6. Para os Baniwa, bem como para a maioria dos povos da região do Alto Rio Negro, o município de São Gabriel da Cachoeira é uma referência importante, pois, localizado estrategicamente nesta porção da Amazônia, é onde recorrem diante de emergências médicas; recebem benefícios sociais, tais como bolsa família; fazem transaçôes bancárias; vendem farinha e outras possibilidades que uma cidade oferece. 
7. Os Distritos Sanitários Especiais Indígenas (DSEI) são unidades organizativas para a operacionalização das açóes de saúde destinadas aos povos indígenas e, portanto, a referência institucional para as comunidades e pessoas que recorrem aos serviços de saúde.

8. O '-nai' é uma partícula coletivizadora, portanto, Ialanawinai é o coletivo dos "brancos", assim como, Kopenai é uma referência ao coletivo dos peixes e Íitsirinai é a referência aos animais em geral. Esta partícula pode indicar também as gentes sociais baniwa: as fratrias e sibs são, assim, muitas vezes, acompanhadas pelo '-nai', como Dzawinai, Waliperedakenai, Komadaminanai.

9. Por estes termos (natureza e/ou cosmologia) quero informar características que conformam uma categoria abrangente que os índios supostamente identificam em nós, os brancos, capaz de refletir e explicar as açôes destas pessoas e seu coletivo. Ou seja, natureza (e/ou cosmologia) branca é neste trabalho uma categoria mediadora, capaz de objetificar as diferenças e, por sua vez, a alteridade não-indígena do ponto de vista indígena. Se nós, por um lado, entendemos os índios ao estudarmos sua cultura, por outro, fica uma questão: qual categoria eles utilizam para entender a nós? Considerando este problema pertinente e supondo que uma categoria conceitual desta espécie exista também para eles, mencionarei o termo 'natureza’ para aludi-la, uma vez que eu não posso nomear este conceito em termos baniwa.

10. Vale ressaltar, para esta discussão, que Alonsio Gentio estudou durante o ensino fundamental e médio na escola Pamáali e, por isso, teve acesso a uma formação educacional diferenciada. A Pamáali tem sua atuação pautada na conciliaçáo de saberes, tradicionais e ocidentais, valorizando o conhecimento baniwa e aquele requerido pelo Ministério da Educação. Não estou sugerindo, no entanto, que a teoria de Alonsio sobre os brancos, tal como foi descrita aqui, seja produto direto desta dita educação escolar diferenciada, mas somente que o modo de objetificar suas concepçôes e comunicá-las, provavelmente, sim.

11. "Benzedores" é o modo como hoje comumente são chamados os 'donos de cânticos', malikai-iminali, que designa um tipo de especialista que atua realizando oraçôes cantadas, ou "rezas" (Wright, 1996).

12. Os Baniwa vieram de Hipana, cachoeira mítica, da qual Napirikoli, o herói criador, retirou os seres humanos.

13. Wagner (2010) propóe que todas as pessoas separam os seus modos de simbolização em um diferenciante e outro convencionalizante, situando cada modo em um reino do dado (inato) ou da ação humana. Contudo, a despeito desse universalismo, cada tradição coloca ênfase em um dos modos e, assim, o que é inato para um não é para outro e vice-versa.

14. A referência a um termo psicanalítico não é fortuito, pois considerei a psicanálise representativa das concepçóes ocidentais de sexualidade, ou pelo menos, das concepçôes que eu compartilho e, como a comparação no caso descrito aqui é comigo, me parece coerente a alusão.

15. O nós neste caso refere-se a um grupo mais circunscrito que o dos "brancos", isso porque durante meu trabalho de campo, além de mim, havia duas pesquisadoras na escola Pamáali, uma antropóloga e uma jornalista.

\section{Referências bibliográficas}

ALBERT, Bruce. O Ouro Canibal e a Queda do Céu: Uma crítica xamânica da economia política da natureza. Série Antropológica, Brasília, n. 174, p. 01 33, 1995.

ERIKSON, Philippe. Qu'est-ce qu'un 'ethnonyme'?: L'exemple matis (Amazonas, Brésil). Cahiers Amérique Latine Histoire et Mémoire, Paris, n. 10, 2004. Disponível em: <http://alhim.revues.org/index112. html> Acesso em: 24 jul. 2011

GALLOIS, Dominique. Gêneses wajāpi, entre diversos e diferentes. Revista de Antropologia, São Paulo, v. 50, n. 1, p. 45-83, 2007.

GARNELO, Luiza. Poder, Hierarquia e Reciprocidade: Os caminhos da política e da saúde no Alto Rio Negro. Tese (Doutorado) - Universidade Estadual de Campinas, São Paulo, 2002.

GEERTZ, Clifford. O saber local. Novos ensaios em antropologia interpretativa. Rio de Janeiro: Vozes, 1997. $366 \mathrm{p}$.

GORDON, Flávio. "O Sexo dos Caracóis": sugestóes para uma Antropologia Reversa, Disparativa e Contra o Estado. (s/d). Disponível em: <https://sites.google. com/a/abaetenet.net/nansi/abaetextos/o-sexo-dos-carac\%C3\%B3is-sugest $\%$ C3\%B5es-para-uma-antropologia-reversa-disparativa-e-contra-o-estado-fl\%C3\%A1vio-gordon> Acessado em 27 out. 2011.

GRUPIONI, Denise. Comparando taxonomias sociais, investigando noçóes de gente. In: VIII Reunião de Antropologia do Mercosul, Buenos Aires, 2009. 
HILL, Jonathan. Cosmology and Situation of Contact in Upper Rio Negro Basin. South American Studies. Bennington, n. 2, p. 42-51, 1993.

. "Musicalizando" o Outro. Ironia ritual e resistência étnica Wakuénai (Venezuela). In. Ramos, Alcida \& Albert, Bruce (Org.). Pacificando o branco. Cosmologias do contato no Norte-Amazônico. São Paulo: Editora UNESP, 2000. p. 347-374.

KOPENAWA, Davi \& ALBERT, Bruce. La Chute du ciel. Paroles d'un chaman yanomami. Paris: Plon, Collection Terre Humaine, 2010. 820 p.

PASSES, Alan. Not alone in the multiverse: borrowing from others, remining Pa'ikwené (Palikur). In: Colóquio Guiana Amerindia (Orgs. NHII/USP \& EREA/ CNRS), Bélem, 2006.

SAHLINS, Marshall. O 'pessimismo sentimental' e a experiência etnográfica: por que a cultura não é um 'objeto' em via de extinção (Parte I). Mana, Rio de Janeiro, v.3, n.1, p.:41-73, 1997.

STRATHERN, Marylin. O Gênero da Dádiva. São Paulo: Unicamp, [1988] 2007. 536 p.

SZTUTMAN, Renato. Jean Rouch, um antropólogo-cineasta. In: Sylvia Caiuby Novaes et alli (Orgs.). Escrituras da Imagem. São Paulo: Edusp, 2004. . Imagens perigosas: a possessão e a gênese do cinema de Jean Rouch. Cadernos de Campo, São Paulo, n. 13, p. 115-124, 2005.

. A utopia reversa de Jean Rouch: de Os mestres loucos a Petit à petit. Revista Devires, Belo Horizonte, v.6, n.1, p. 108-125, 2009.

VIANNA, João. De volta ao caos primordial. Alteridade, indiferenciação e adoecimento entre os Baniwa. Disser- tação (Mestrado) - Universidade Federal do Amazonas, Manaus, 2012.

VIVEIROS DE CASTRO, Eduardo. Os pronomes cosmológicos e o perspectivismo ameríndio. Mana, Rio de Janeiro, v. 2, n. 2, p.115-144, 1996.

Perspectival Anthropology and the method of controlled equivocation. Tipiti, New Orleans, v. 2, n.2, p. 03-22, 2004.

Se tudo é humano, então tudo é perigoso. In: Sztutman, Renato (Org.). Eduardo Viveiros de Castro - Entrevistas. Rio de Janeiro: Beco do Azougue, 2008.

WAGNER, Roy. A invenção da Cultura. Rio de Janeiro: CosacNaify, [1981] 2010. 256 p.

WRIGHT, Robin. (Org.) Waferinaipe Ianheke: a sabedoria dos nossos antepassados: histórias dos Hohodene e dos Walipere-Dakenai do rio Aiari. São Gabriel da Cachoeira: FOIRN/ACIRA, 1999. 192 p.

Ialanawinai. O branco na história e mito

Baniwa. In. Ramos, Alcida \& Albert, Bruce (Orgs.). Pacificando o branco. Cosmologias do contato no Norte-Amazônico. São Paulo: Editora UNESP, 2000. p 431-468

História indígena e do indigenismo no Alto Rio Negro. São Paulo: ISA, 2005. 320 p.

XAVIER, Carlos. A cidade grande de Napirikoli e os petroglifos do Içana: uma etnografia de signos Baniwa. Dissertação (Mestrado) - Museu Nacional, Rio de Janeiro, 2008.

autor Joáo Jackson Bezerra Vianna
Mestre em Antropologia Social / PPGAS - UFAM

Recebido em 04/03/2012

Aceito para publicação em 01/10/2012 